\title{
Influence of the type of fiber on the structural response and design of FRC slabs
}

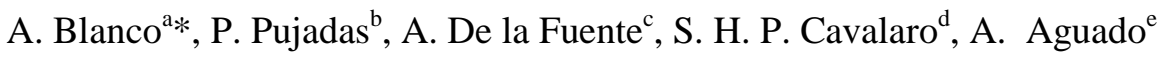 \\ ${ }^{a}$ Department of Construction Engineering, Universitat Politècnica de Catalunya, UPC, Jordi Girona 1-3, 08034 Barcelona, Spain. \\ E-mail:ana.blanco@upc.edu \\ ${ }^{b}$ Department of Construction Engineering, Universitat Politècnica de Catalunya, UPC, Jordi Girona 1-3, 08034 Barcelona, Spain. \\ E-mail: pablo.pujadas@upc.edu \\ ${ }^{c}$ Department of Construction Engineering, Universitat Politècnica de Catalunya, UPC, Jordi Girona 1-3, 08034 Barcelona, Spain. \\ E-mail: albert.de.la.fuente@upc.edu \\ ${ }^{d}$ Department of Construction Engineering, Universitat Politècnica de Catalunya, UPC, Jordi Girona 1-3, 08034 Barcelona, Spain. \\ E-mail: sergio.pialarissi@upc.edu \\ ${ }^{e}$ Department of Construction Engineering, Universitat Politècnica de Catalunya, UPC, Jordi Girona 1-3, 08034 Barcelona, Spain. \\ E-mail: antonio.aguado@upc.edu \\ * Corresponding author Tel.: +34-93-401-7825; fax: +34-93-401-1036; e-mail: ana.blanco@upc.edu
}

\begin{abstract}
Most codes for the design of fiber reinforced concrete (FRC) structures are based on the experience achieved throughout the years with steel fibers. Recent codes include the possibility of applying the same considerations for FRC structures with plastic fiber. However, the consequences of assuming identical design considerations regardless of the type of fiber is scarcely known in terms of the structural behavior of full-scale elements. The main goal of this paper is to assess the influence of the type of fiber on the performance of full-scale concrete slabs, emphasizing on the consequences of using a common design approach. For that, a comparative experimental study was conducted in order to expose differences regarding the crack pattern and load-deflection behavior. Then, finite element simulations were performed using the constitutive equations from the Model Code 2010. The results indicate distinct levels of overestimation of the structural behavior measured experimentally, confirming that specific design considerations are required depending on the type of fiber used. Based on the findings, correction factors are proposed for the design of FRC slabs with each fiber.
\end{abstract}

Keywords: slabs, steel fiber, plastic fiber, design, Model Code

\section{INTRODUCTION}

Fibers are extensively used as primary reinforcement in concrete structures when the design is governed by transient load stages (e.g. precast segments for tunnels), in elements with favorable boundary conditions or structures subjected to low load levels (e.g. pavements or pipes) (De la Fuente et al. 2012, De la Fuente et al. 2013, Belletti et al. 2008, Nobili et al. 2013). The material has also been applied as the only reinforcement in elements subjected to higher load levels, as in slabs (Soranakom et al. 2007, Destrée and Mandl 2008, Maturana et al. 2010) or thin-wall roof elements (Di Prisco et al. 2013). Interestingly, steel fibers were used in almost all examples of application reported in the literature. Such situation arises partly from the fact that the design considerations from the first codes and guidelines were based on the experience gained throughout the years with steel fiber reinforced concrete (SFRC). As a result, the use of other types of fibers was not contemplated in the design.

Nevertheless, the latest codes (e.g. Model Code 2010 (FIB 2010)) also include the possibility of designing structures with plastic fiber reinforced concrete (PFRC). Despite the well-known differences in terms of mechanical properties and pullout response, almost no distinction in the design is made depending on the type of fiber. In fact, the same considerations apply equally to SFRC and PFRC. 
This sides with the absence of studies from the literature dedicated to the comparison of the behavior of full-scale elements with SFRC and with PFRC. Most of the studies found focus on the comparison of results from small-scale tests (Buratti et al. 2011), which are hardly representative of the real structure in terms of fiber distribution. The ones that evaluate the behavior of large-scale elements usually focus either on the comparison between elements with fibers and with traditional reinforcement (Pujadas et al. 2012) or on the analysis of only one type of fiber. In line with this, recent studies evaluated the experimental response of slabs reinforced only with fibers and addressed the applicability of the current constitutive models to estimate their flexural performance (Michels et al. 2012, Pujadas et al. 2014a, Blanco et al. 2015a).

In particular, Blanco et al. (2015a) and Pujadas et al. (2014a) tested full-scale slabs reinforced only with steel and plastic fibers, respectively. Although the results obtained shed light on specificities regarding the behavior of full-scale slabs with each type of fiber, no direct comparison was made among them. Consequently, the consequences of assuming identical design consideration regardless of the material of the fiber are not evident in this case.

Considering the above, the main goal of this paper is to assess the influence of the type of fiber on the performance of full-scale concrete slabs, emphasizing on the consequences of using a common design approach. With such intent, an overview of the main differences regarding the pullout behavior of plastic and steel fibers is presented. Then, a comparative study based on the experimental program by Pujadas et al. (2014a) and Blanco et al. (2015a) was conducted to expose differences in terms of crack patterns and load-deflection behavior directly related with particularities of the pullout response of each fiber. Subsequently, finite element simulations of the tests were performed using the constitutive equation from the Model Code 2010.

This study provides valuable information on the differences that may arise in full-scale elements depending on the type of fiber while offering a critical analysis of the prescriptions of the Model Code 2010. The conclusions derived may help the development of future codes, highlighting the specificities related with the fiber type. The experimental and numerical results also serve as a reference for engineers that have to decide between SFRC and PFRC in real structural applications.

\section{FIBER PULLOUT MECHANISM}

Fiber pullout is the mechanism governing the post-cracking behavior of fiber reinforced concrete (FRC) under tensile stresses (Naaman et al. 1991, Taerwe and Gysel 1996). A review of this mechanism may be of great interest to comprehend how the type of fiber influences the structural response of structures. In general, the pullout of steel fibers involves 4 stages: debonding, matrix spalling, frictional sliding and removal (Laranjeira et al. 2010a, Laranjeira et al. 2010b). In the first of these stages, after the crack is formed, tensile forces are transmitted from the matrix through tangential stresses that act on the surface of the fiber (Jenq and Shah 1986; Naaman et al. 1991). Once the stresses reach the bond strength between materials, debonding takes place (Fig. 1) (Soetens et al. 2013).

As the crack opens, the curvature of the fiber increases, generating local stresses close to the crack mouth. When the stresses reach critical levels, matrix spalling might occur. According to Singh et al. (2004), this local failure takes place after the beginning of fiber debonding. In the 
case of hooked-end fibers, the hook deforms plastically when the debonding is not yet completed. Due to these plastic deformations, the force needed to pullout the fiber becomes larger and the volume of matrix spalled off increases. After the whole embedded length is debonded, the fiber slides progressively and the friction forces are activated as a result of the relative displacement between the fiber and the surrounding matrix (Soetens et al. 2013). Fiber may be completely removed from the matrix if enough displacement occurs.

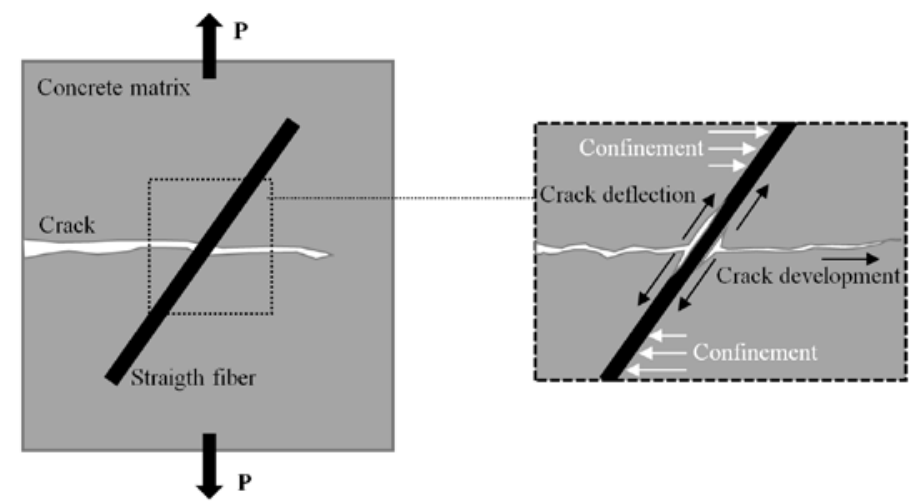

Fig. 1 Schematic representation of debonding stage, adapted from (Laranjeira et al. 2010a)

Even though the described stages may be also applicable to plastic fibers (Singh et al. 2004), several aspects with regard to the behavior should be clarified. On the one hand, the modulus of elasticity of plastic fibers is around 20 times smaller than that of steel fibers (Buratti et al. 2011). This means that, under tensile forces, plastic fibers will show larger displacement due to stretching before the debonding stage starts. In other words, plastic fibers might require bigger crack opening to start contributing to the transmission of stresses. Consequently, the reduction of stiffness after cracking tends to be higher in PFRC than in SFRC. This is observed in the pullout mechanism and in other indirect tensile tests in the form of a steeper reduction in the load after cracking in the case of PFRC.

Moreover, the tensile strength of plastic fibers is usually lower than that of steel fibers. Therefore, depending on the strength of the concrete matrix and its bond with plastic fibers, the latter may break instead of slide, which may lead to lower pullout loads. Studies also indicate that the additional force provided by the curvature of the plastic fibers may be negligible due to their low bending stiffness ( $\mathrm{Li}$ et al. 1990). Therefore, the influence of the orientation of the plastic fibers on the pullout may be smaller than in the case of the steel fibers.

\section{EXPERIMENTAL INVESTIGATION}

Even though the experimental programs are described in detail in (Pujadas et al. 2014a) and (Blanco et al. 2015a), a brief presentation is included in this section to facilitate the comprehension of the analysis performed afterwards.

\section{Specimens}

Slabs were cast with $3.0 \mathrm{~m}$ of length, $0.2 \mathrm{~m}$ of thickness and width equal to $1.5 \mathrm{~m}, 2.0 \mathrm{~m}$ and 3.0 $\mathrm{m}$ (hereinafter called slabs S, M and L, respectively). These dimensions reproduce the typical sizes found in practice. The change in the width also allowed the assessment of the internal 
redistribution of forces and the deformability experienced by the elements depending on the type of fiber. In total, 2 slabs were produced per each size. The notation adopted to refer to the slabs is presented in Table 1 . The acronym SF is added to the notations to indicate the use of steel fiber, whereas PF indicate the use of plastic fiber. The letters A or B are appended to the end of the notation to make reference to each of the two slabs with the same dimension.

Table 1. Notation adopted

\begin{tabular}{ccc}
\hline Notation & Fiber & Dimensions (m) \\
\hline S_SF_A or_B & Steel & \multirow{2}{*}{$1.5 \times 3.0 \times 0.2$} \\
S_PF_A or_B & Plastic & \\
\hline M_SF_A or_B & Steel & \multirow{2}{*}{$2.0 \times 3.0 \times 0.2$} \\
M_PF_A or_B & Plastic & \\
\hline L_SF_A or_B & Steel & \multirow{2}{*}{$3.0 \times 3.0 \times 0.2$} \\
L_PF_A or_B & Plastic & \\
\hline
\end{tabular}

\section{Material properties}

A fluid concrete with characteristics close to self-compactability was used. Table 2 shows the composition of the concrete. In order to define the fiber content, two approaches were initially contemplated: to achieve a similar residual strength in SFRC and PFRC or to maintain the same number of fibers in both cases. Notice that it is technically difficult to obtain similar residual strengths for the whole extent of the stress-strain curve given that particularities in the pullout response of each fiber would yield different trends. Although the value of the residual strength for a certain crack openings could be the same, differences might arise for other crack openings. Furthermore, in the first approach, not only the material but also the number of fibers added changes.

On the contrary, the only variable related with the composition modified in the second approach is the material of the fiber. Since the aim of this study is to provide a direct assessment of the influence of the type of fiber, the second approach was chosen as it limits the number of variables taken into account. Based on such criterion and on previous experience, the fiber contents of $40 \mathrm{~kg} / \mathrm{m}^{3}$ ( $0.5 \%$ by volume) and $9 \mathrm{~kg} / \mathrm{m}^{3}$ (1.0\% by volume) were selected for steel and plastic fibers, respectively. These contents are equivalent to approximately 320.000 fibers per cubic meter of concrete.

Table 2. Concrete compositions

\begin{tabular}{lcc}
\hline \multirow{2}{*}{ Materials } & \multicolumn{2}{c}{ Content $\left(\mathbf{k g} / \mathbf{m}^{3}\right)$} \\
\cline { 2 - 3 } & SFRC & PFRC \\
\hline Gravel 6/15 mm & 520 & 520 \\
Gravel 2.5/6 mm & 400 & 400 \\
Sand 0/3 mm & 510 & 510 \\
Cement & 350 & 350 \\
Filler & 300 & 300 \\
Water & 178 & 178 \\
Superplasticizer & 12 & 12 \\
Fibers & 40 & 9 \\
\hline
\end{tabular}

The steel fibers have a circular cross-section with $0.62 \mathrm{~mm}$ of diameter and $50 \mathrm{~mm}$ of length with hooked ends, being gathered in bundles by water-soluble glue (see Fig. 2b). They are made 
of low carbon steel with tensile strength $\left(f_{t}\right)$ of $1270 \mathrm{MPa}$ and modulus of elasticity of $210 \mathrm{MPa}$. The plastic fibers are derived from polyolefin (specifically from polypropylene) and have continuously embossed surface texture to improve adherence (see Figure 2c). Their tensile strength and their modulus of elasticity are $550 \mathrm{MPa}$ and $10 \mathrm{GPa}$, respectively. Notice that both fibers selected have nearly the same length to avoid introducing new variables. Fig. 2a shows an example of the load-crack mouth opening displacement (CMOD) curves obtained with each type of fiber in the bending test according to UNE 83507:2004.

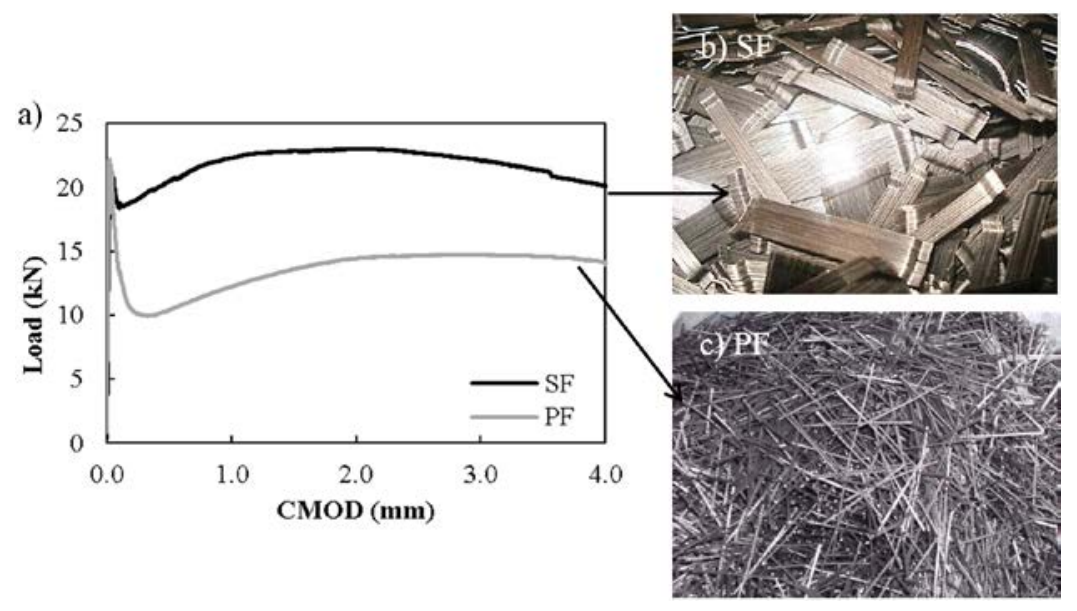

Fig. 2 a) Load-CMOD curves, b) steel fibers (SF) and c) plastic fibers (PF)

The concrete was poured from the center of the slabs with a straight outlet skip that stood between 60 and $100 \mathrm{~cm}$ above the surface of the formwork. Given the influence of the pouring method in the orientation of the fibers, the same casting procedure was apploed throughout the production process. The concrete did not show any sign of segregation and the fibers were uniformly distributed in the mass. After pouring, the concrete was vibrated externally for 15 to 20 seconds with a portable system of vibrators attached to the walls of the formwork to ensure proper compaction and to reduce the volume of occluded air. The slabs were removed from the molds 24 hours after casting, moist cured under a plastic sheet during 20 days and kept under indoor laboratory conditions until the moment of testing.

Table 3 summarizes the average values of compressive strength $\left(f_{c m}\right)$ and modulus of elasticity $\left(E_{c m}\right)$ at 28 days, obtained according to UNE 83507:2004 (AENOR 2004) and UNE 83316:1996 (AENOR 1996), respectively. The proportionality limits $\left(f_{L}\right)$ and the residual flexural tensile strengths $f_{R 1}, f_{R 2}, f_{R 3}$ and $f_{R 4}$ were determined according to EN 14651:2005 (CEN 2005). The results of $f_{c m}$ and $E_{c m}$ correspond to the average of three test, whereas the flexural results correspond to the average of six tests (except for batch SF3 in which only three beams were available for testing and one of them failed due to problems with the CMOD control).

The modulus of elasticity and the compressive strength obtained for the SFRC do not show significant differences with that obtained for the PFRC. Conversely, the residual flexural tensile strength indicates a better performance of the SFRC. In fact, the average values of $f_{R 1}, f_{R 2}, f_{R 3}$ and $f_{R 4}$ of the SFRC are $94.2 \%, 70.6 \%, 50.4 \%$ and $39.3 \%$ bigger than their equivalents in the case of PFRC. Such outcome may be attributed to the low modulus of elasticity of PF and the differences in terms of pullout mechanism described in the previous section. 
Table 3. Modulus of elasticity, compressive strength and residual flexural strength at 28 days

\begin{tabular}{|c|c|c|c|c|c|c|c|c|c|c|c|c|}
\hline \multirow[b]{2}{*}{ Properties } & \multicolumn{2}{|c|}{ Batch SF1 } & \multicolumn{2}{|c|}{ Batch SF2 } & \multicolumn{2}{|c|}{ Batch SF3 } & \multicolumn{2}{|c|}{ Batch PF1 } & \multicolumn{2}{|c|}{ Batch PF2 } & \multicolumn{2}{|c|}{ Batch PF3 } \\
\hline & $\begin{array}{c}\text { Average } \\
\text { (MPa) }\end{array}$ & $\begin{array}{l}C V \\
(\%)\end{array}$ & $\begin{array}{c}\text { Average } \\
(\mathrm{MPa})\end{array}$ & $\begin{array}{l}C V \\
(\%)\end{array}$ & $\begin{array}{c}\text { Average } \\
(\mathrm{MPa})\end{array}$ & $\begin{array}{l}C V \\
(\%)\end{array}$ & $\begin{array}{c}\text { Average } \\
(\mathrm{MPa})\end{array}$ & $\begin{array}{l}C V \\
(\%)\end{array}$ & $\begin{array}{c}\text { Average } \\
\text { (MPa) }\end{array}$ & $\begin{array}{l}C V \\
(\%)\end{array}$ & $\begin{array}{c}\text { Average } \\
(\mathrm{MPa})\end{array}$ & $\begin{array}{l}C \mathrm{CV} \\
(\%)\end{array}$ \\
\hline$E_{c m}$ & 29030 & 0.96 & 28640 & 2.79 & 30160 & 2.20 & 32000 & 0.74 & 33200 & 1.49 & 29900 & 5.65 \\
\hline$f_{c m}$ & 46.73 & 0.77 & 49.46 & 0.59 & 46.77 & 2.54 & 46.40 & 2.44 & 47.99 & 1.85 & 50.54 & 2.41 \\
\hline$f_{L}$ & 5.42 & 7.05 & 5.29 & 2.23 & 3.76 & 7.96 & 4.82 & 7.71 & 4.83 & 7.07 & 4.34 & 10.92 \\
\hline$f_{R 1}$ & 6.25 & 12.50 & 6.13 & 13.71 & 3.75 & 22.29 & 3.56 & 8.47 & 3.04 & 11.95 & 2.96 & 31.01 \\
\hline$f_{R 2}$ & 7.02 & 12.39 & 7.04 & 15.77 & 4.24 & 17.91 & 4.70 & 6.05 & 3.94 & 11.62 & 3.72 & 34.67 \\
\hline$f_{R 3}$ & 7.05 & 11.59 & 7.08 & 15.05 & 4.30 & 15.88 & 5.19 & 4.81 & 4.36 & 11.38 & 4.54 & 36.0 \\
\hline$f_{R 4}$ & 6.62 & 12.08 & 6.62 & 12.08 & 4.17 & 15.68 & 5.23 & 5.17 & 4.42 & 10.60 & 4.61 & 34.56 \\
\hline Slabs & \multicolumn{2}{|c|}{$L \_S F \_A, M \_S F \_A$} & \multicolumn{2}{|c|}{$L \_S F \_B, M \_S F \_B$} & \multicolumn{2}{|c|}{$S \_S F \_A, S \_S F \_B$} & \multicolumn{2}{|c|}{$L \_P F \_A, M \_P F \_A$} & \multicolumn{2}{|c|}{$L \_P F \_B, M \_P F \_B$} & \multicolumn{2}{|c|}{$S \_P F \_A, S \_P F \_B$} \\
\hline
\end{tabular}

Fig. 2a shows typical load-CMOD curves for SFRC and PFRC. Notice that the maximum contribution of the steel fibers is observed for $C M O D$ between $1.5 \mathrm{~mm}$ and $2.5 \mathrm{~mm}$. For larger displacements, the load decreases progressively. On the contrary, the maximum contribution of the plastic fibers occurs for $C M O D$ close to $4.0 \mathrm{~mm}$, when the test finishes. The coefficient of variation $(C V)$ of the residual strengths indicates that the SFRC used here presents higher scattering than the PFRC (with the exception of batch PF3). These results are consistent with the findings by Buratti et al. (2011), which show that fibers with bigger elastic modulus are prone to higher scattering.

Notice that batches SF1 and SF2 exhibit almost identical mechanical properties, while batch SF3 presents lower residual strength. This difference is attributed to the small number of beams tested in SF3. Since other properties are the same for the three batches with steel fiber, it is considered that the average residual flexural tensile strength from batches SF1 and SF2 also apply to batch SF3.

\section{Test setup and testing procedure}

The slabs were simply supported on steel trestles along the central half of the sides (see Fig. 3). This setup reproduces a hyperstatic support condition that allows an internal redistribution of forces and the contribution of fibers in more than one direction. The load was applied with a servo-hydraulic jack at a neoprene sheet (200 x $200 \times 20 \mathrm{~mm})$ placed at the center of the slab. Neoprene sheets were also placed between the slab and the steel trestles to limit the contact area and to guarantee a more uniform load transmission. In this case, the neoprene sheets were 20 mm thick, $200 \mathrm{~mm}$ wide and had a length equal to half the side of the slab.

The load and the displacement of the piston were measured throughout the test. The deflection was also assessed in different points of the slab by means of 14 magnetostrictive displacement transducers placed on the top surface (see Fig. 3). A reticular structure was built in order to hold the transducers along the symmetry axes (six in each direction and at two diagonally opposed corners) and over the supports. The displacement transducers placed in the largest direction were separated $53 \mathrm{~cm}$ apart. In the shortest direction, the distance was variable depending on the width of the slab. Further details on the test setup and the measurements taken are found in the previously referred studies by the authors. 

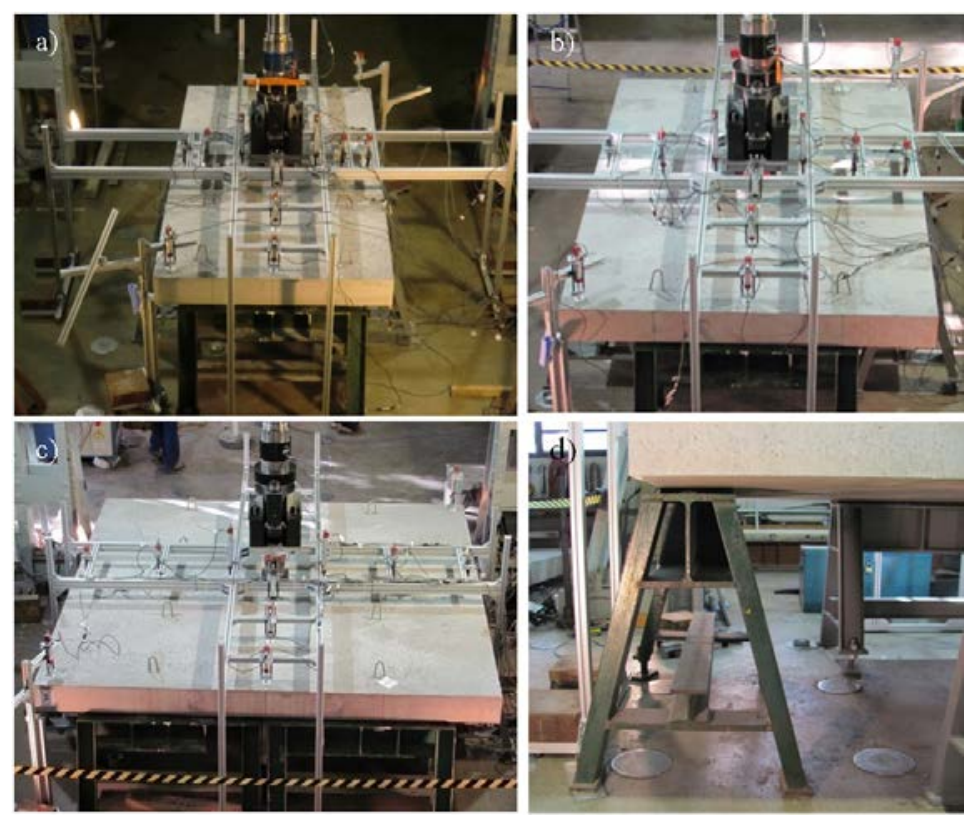

Fig. 3 Setup for slabs a) S, b) M, c) L (Blanco et al. 2015a) and d) detail of the support

Tests were performed with displacement control of the jack, following a load procedure divided in two sequential stages. At the first stage, a smaller displacement rate was used to allow a clear observation of the formation and the propagation of cracks. Since the flexibility of the elements tested increases with the width, displacement rates of $0.15 \mathrm{~mm} / \mathrm{min}, 0.20 \mathrm{~mm} / \mathrm{min}$ and 0.25 $\mathrm{mm} / \mathrm{min}$ were adopted for slabs S, M and L, respectively. Once the major cracks had stabilized, the rate was increased to assess the behavior of the slabs for high deflections. Values of 0.20 $\mathrm{mm} / \mathrm{min}, 0.30 \mathrm{~mm} / \mathrm{min}$ and $0.40 \mathrm{~mm} / \mathrm{min}$ were used in the second stage for slabs $\mathrm{S}, \mathrm{M}$ and $\mathrm{L}$, respectively.

It is important to remark that the dimensions of the slabs, the test setup and the strength of concrete were also selected to assure a failure caused by pure bending. According with analytic calculations with the parameters from Table 3 and the yield line theory (Johansen 1962), maximum cracking loads between $100 \mathrm{kN}$ and $400 \mathrm{kN}$ were expected due to bending. These values are smaller than the load required to produce failure due to punching shear, which is around $500 \mathrm{kN}$ according with analytic calculations.

\section{RESULTS AND DISCUSSION}

\section{Failure mechanism and crack patterns}

Fig. 4 depicts the crack patterns of the slabs after the test. As anticipated, no clear sign of punching or shear failure was present, thus indicating a failure governed mainly by bending. A set of primary (black lines) and secondary (grey lines) cracks extends from the center to the edges. This pattern is consistent with that expected according to the yield line theory (Johansen 1962). Four main cracks appear in the slabs with the exception of M_SF_B, M_PF_A and L_SF_A that exhibit five main cracks. This could lead to differences in the post-cracking behavior in comparison with their corresponding pair.

SFRC slabs present a bigger number of secondary cracks than PFRC slabs. Such difference is particularly evident in slabs $\mathrm{M}$ and $\mathrm{L}$ since they reached larger deformation during the test. The 
reason for such behavior is the higher capacity of the SF to transmit stresses at the cracked section through their bond with the concrete matrix.
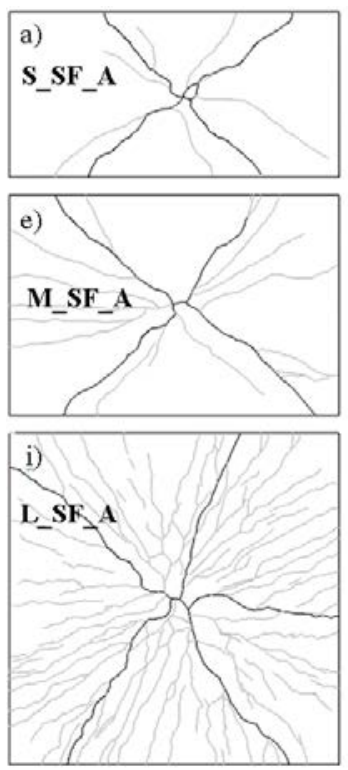
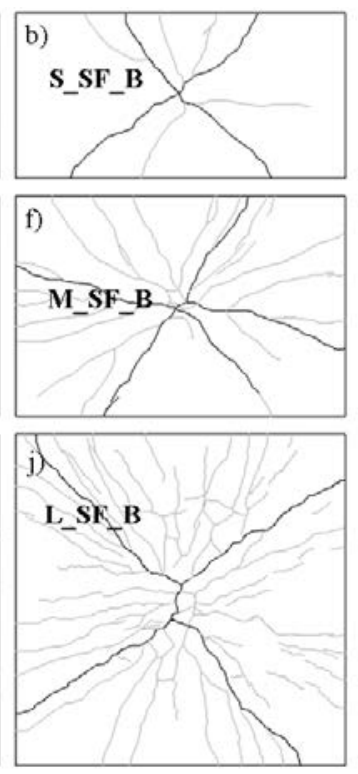
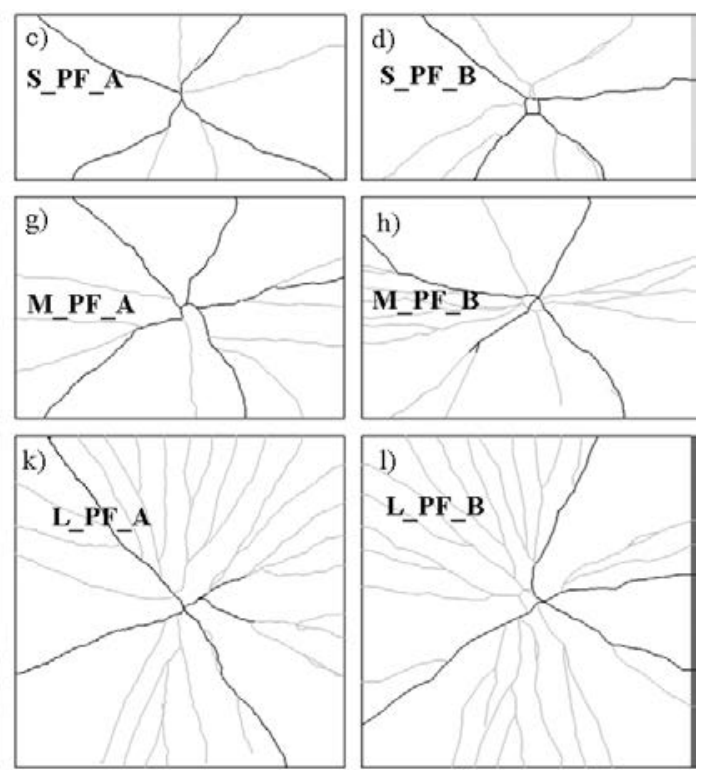

Fig. 4 Crack patterns of the slabs

Notice that after cracking, the reduction of stiffness in the affected section is less significant for SFRC slabs due to the properties of the fiber. Therefore, the cracked sections of the SFRC slabs are activated in terms of transmission of tensile stresses for smaller crack openings. Consequently, adjacent sections may reach critical stresses and crack as well. This increases the number of secondary cracks, contributes to a higher redistribution of internal forces and to the global capacity of the slab to bear additional loads.

On the contrary, the reduction of stiffness experienced in PFRC cracked sections is more abrupt. A bigger crack opening is required in order to activate these fibers. Hence, a larger extent of the cracked sections is damaged before enough tensile strength is reached to form the secondary cracks. This explains the smaller number of secondary cracks found for the same level of deflection in the case of PFRC slabs.

\section{Load-deflection behavior}

Fig. 5 shows the load-deflection $(P-\delta)$ curves measured during the test of all slabs. They reveal a significant difference in the structural behavior depending on the type of fiber used. In order to comprehend the reasons for that, an analogy is made between the curves and the pullout behavior of a single fiber.

The load resisted by SFRC slabs increases after cracking and reaches values that are significantly higher than those of PFRC slabs. The maximum load registered in this case is related with the maximum contribution of the fiber, which tends to be higher for SFRC. As the deflection increases, the load resisted decrease due to the progressive sliding of the fibers inside the concrete matrix, particularly once the hooked-ends have been straightened. 

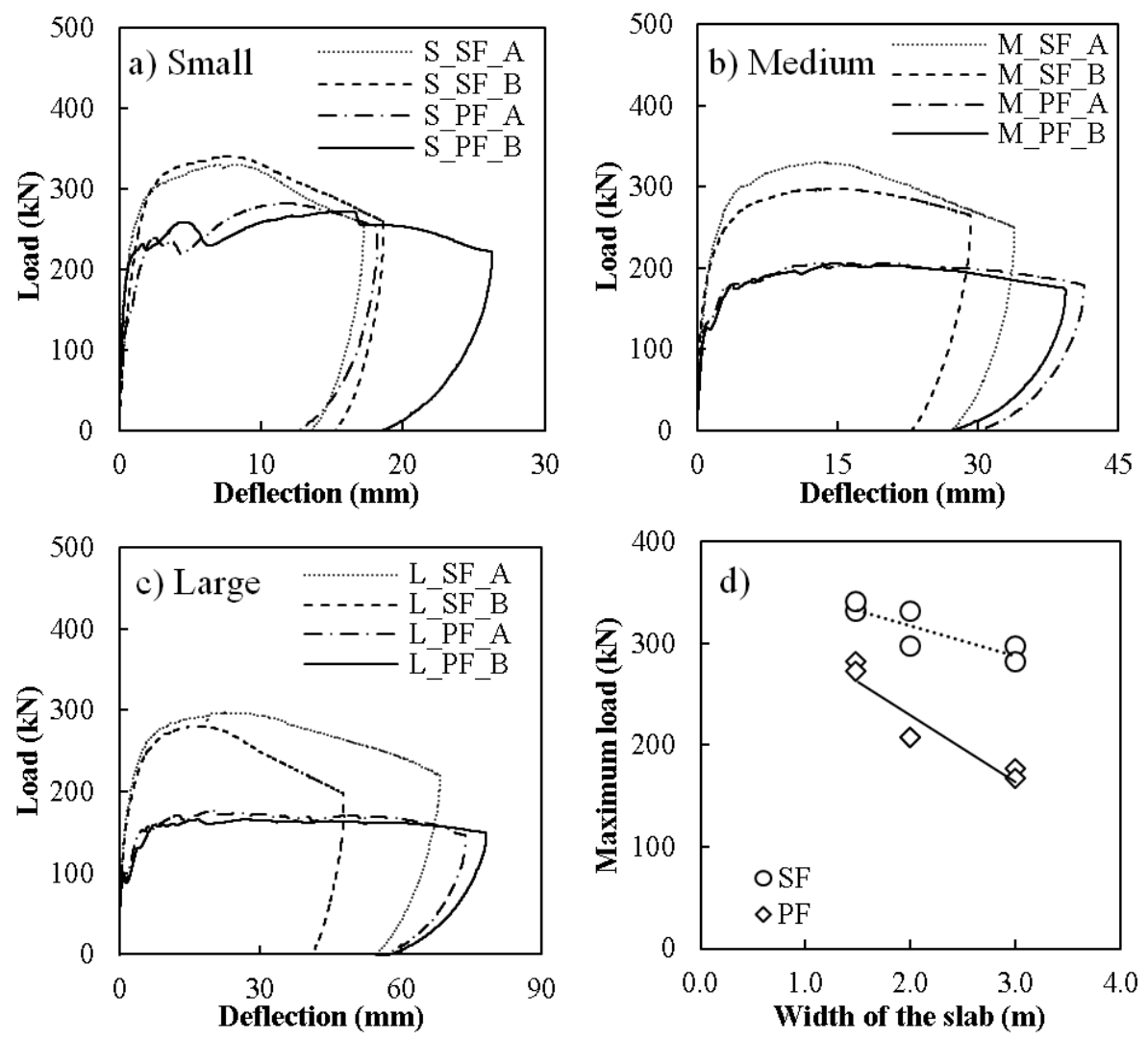

Fig. 5 P- $\delta$ curves of slabs S (a), M (b) and L (c) and evolution of the maximum load with the width (d)

A different behavior is detected in the PFRC slabs that exhibit a slight drop of load due to the cracking for very small deflection values. This drop is related to the reduction of stiffness experienced in the pullout of PF just after cracking. Notice that such reduction of stiffness could compromise the serviceability limit state requirements established in project. This should be taken into account in the design of PFRC structures. Fibers become active as deflection increases, allowing the application of additional load. Once the maximum is reached, the load remains approximately constant until the end of the test. Like in the pullout results, the lower modulus of the PF allows them to stretch and to slip with a small reduction in the load.

The scattering in the results of the PFRC slabs is smaller than that of SFRC slabs with the same size. This may be associated to the influence of the fiber properties when alterations in fiber distribution occur inside the concrete matrix. In the case of PF, it is hypothesized that differences in distribution have less influence in the global response of the slabs since the modulus of elasticity of PF allows them to bend and align with the force applied, thus being less sensible to variations in the angle formed with the cracked plane. Besides, the lower pullout load PF decreases the likelihood of spalling of the matrix during the pullout and reduces the variability for a wider range of angles formed with the cracked plane. Conversely, SF are less capable of bending and aligning with the force applied and are more likely to produce spalling of the matrix due to the higher pullout loads reached. In other words, SFRC should be more sensible to variations in the fiber orientation.

Fig. $5 \mathrm{~d}$ shows the maximum load reached in the test depending on the size of the slab. As expected, the maximum load decreases as the width increases. Interestingly, the differences 
between the SFRC and PFRC slabs become more evident as the size of the slab increases. For a width of $1.5 \mathrm{~m}$, the average result of SFRC slabs is $21.0 \%$ bigger than that of PFRC slabs. The same difference increases to $51.8 \%$ in the case of the slabs with $2.0 \mathrm{~m}$ of width and to $68.6 \%$ for the slabs with $3.0 \mathrm{~m}$ of width. This may be caused by the stress transmission capacity of each fiber and is indirectly related to the density of secondary cracks shown in Figure 4. SF generates alternative resistant paths inside the slabs, increasing the load bearing capacity of the structure. The contribution of SF becomes more noticeable in larger elements that are subjected to bigger deflection and present a significant increase in the number of secondary cracks. Conversely, the reduction of stiffness experienced by PF just after cracking hinders the formation of alternative resistant paths. Because of that, the reduction of the maximum load with the increase of the width is more evident in the PFRC slabs than in the case of SFRC slabs.

\section{NUMERICAL MODEL}

\section{Description of the model}

The tests were simulated with the finite element software ATENA 4.3.1g (Cervenka 2000) that includes specific materials models for the 3D analysis of FRC elements. The tensile behavior of concrete is modeled by non-linear fracture mechanisms combined with the crack band method and the smeared crack approach.

The nonlinear stress-strain constitutive diagram in compression proposed by the Model Code 2010 was used. In tension, the diagram proposed by the same code for FRC was selected. As shown in Fig. 6, the latter diagram presents a branch up to the cracking of the material once the tensile strength $\left(\sigma_{2}\right)$ is reached. Afterwards, fibers provide a residual strength that is represented by the post-peak branch in Fig.6, defined by $\sigma_{3}$ and $\sigma_{4}$. This branch may show a strain-softening or strain-hardening behavior, depending on the type of concrete and fiber content. The ultimate strain is defined by $\varepsilon_{4}$. The parameters of the diagram are derived from the load-CMOD curves obtained in the small-scale bending tests described in EN 14651:2005 (CEN 2005). The Model Code 2010 also includes an orientation factor $(K)$ that takes into account beneficial and nonbeneficial fiber orientations.

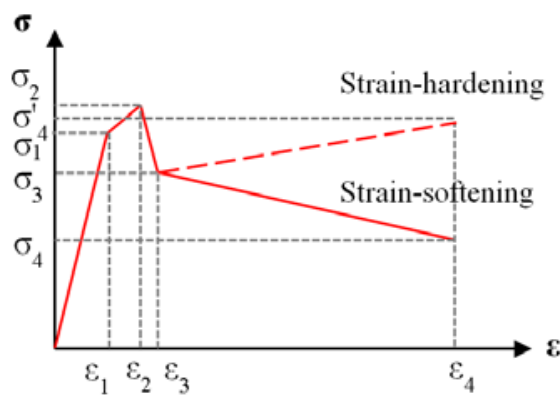

Fig. 6 Constitutive diagram in tension used for the simulation of FRC

The biaxial failure criterion according to Kupfer et al. (1969) was considered in the simulations. The crack band size is automatically calculated by ATENA according to the crack band theory (Bazant and Oh 1993). The characteristic length used to estimate the strain was defined according to previous studies that suggest a constant value ranging from half the size of the specimen to the double of the size for SFRC elements without any other type of reinforcement (De Montaignac et al. 2012). These values are consistent with the finite element models 
defining the extent of the crack influence zone close to the member depth on both sides of the crack (Kooiman 2000). In the present study, the characteristic length adopted to estimate the strain is half the thickness of the slabs as suggested by de Ultkjaer et al. (1995), Pedersen (1996), Iyengar (1998), Kooiman (2000), RILEM 2002, De Montaignac et al. (2012).

A tetrahedral finite element mesh was refined to reproduce localized cracking observed in the experimental program without increasing excessively the time required for the calculation. Symmetry of the slabs was assumed in order to reduce the number of elements and the calculation time. Previous studies demonstrated that modeling a quarter of the slabs yields almost identical results to the ones obtained with the simulation of the whole slab (Blanco et al. 2015b). The neoprene sheets located in the load application point and in the supports were also modeled to assure a realistic representation of the boundary conditions. Interface elements were placed between all neoprene sheets and the slab in order to simulate the contact properties found in reality (see Fig. 7).
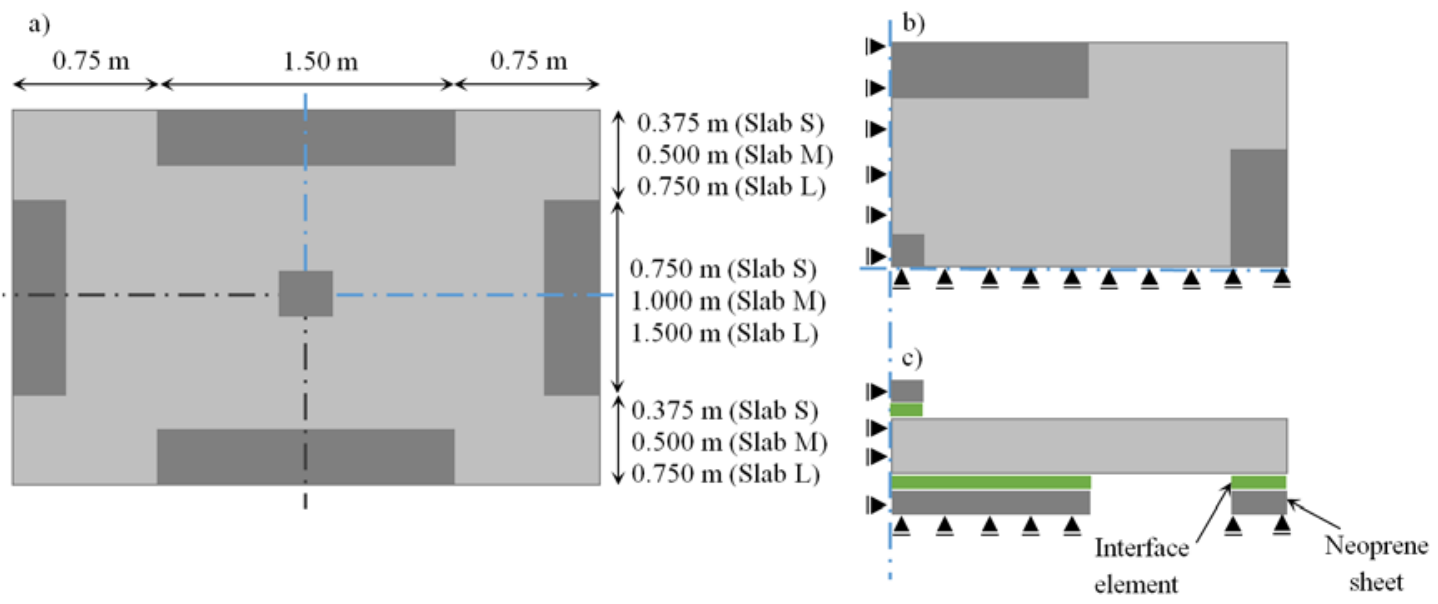

Fig. 7 Bottom view of the whole slab (a), bottom view (b) and side view (c) of the one quarter of the slab modeled

Simply supported conditions were imposed by restraining the vertical displacement at the bottom face of the neoprene. The displacement perpendicular to the symmetry planes was also restrained. The load case consisted of a vertical displacement acting simultaneously at all nodes of top face of the neoprene sheet.

The material properties measured experimentally for the concrete and the neoprene sheets were introduced in the model. The interface elements follow a Coulomb friction model. The properties of all materials and interfaces are summarized in Table 4. Notice that for models M_SF and L_SF the properties of batch SF1 were considered, whereas for M_PF and L_PF properties of batch PF1 were used. As mentioned previously, the equations proposed by the Model Code 2010 were used to convert the load-CMOD relation from the small-scale tests into a stress-strain curve in tension for the finite element simulations. Furthermore, an isotropic orientation of the fibers was assumed, thus leading to a $K$ equal to 1.0 . 
Table 4. Properties of the material defined in the ATENA-models

\begin{tabular}{|c|c|c|c|c|}
\hline Model & Model part & Material properties & Value & Reference \\
\hline \multirow{7}{*}{$\begin{array}{l}\text { Common } \\
\text { properties for } \\
\text { all models }\end{array}$} & \multirow{2}{*}{$\begin{array}{l}\text { Neoprene } \\
\text { sheets }\end{array}$} & Average modulus of elasticity [MPa] & 35.0 & EN1337-3:2005 (CEN 2005) \\
\hline & & Poisson ratio $[-]$ & 0.3 & - \\
\hline & \multirow{5}{*}{$\begin{array}{l}\text { Interface } \\
\text { material }\end{array}$} & Normal stiffness $\left[\mathrm{MN} / \mathrm{m}^{3}\right]$ & $2.0 \cdot 10^{8}$ & - \\
\hline & & Tangential stiffness $\left[\mathrm{MN} / \mathrm{m}^{3}\right]$ & $2.0 \cdot 10^{8}$ & - \\
\hline & & Cohesion $[\mathrm{MPa}]$ & 0 & - \\
\hline & & Friction coefficient & 0.5 & - \\
\hline & & Cut-off traction stress [MPa] & 0 & - \\
\hline \multirow{12}{*}{ Model S } & \multirow{12}{*}{$\begin{array}{c}\text { Slab } \\
\text { (SF/PF) }\end{array}$} & Average compressive strength [MPa] & $46.8 / 50.5$ & UNE 83507:2004 \\
\hline & & Average modulus of elasticity [GPa] & $30.6 / 29.9$ & UNE 83316:1996 \\
\hline & & Poisson ratio $[-]$ & 0.2 & Model Code 2010 \\
\hline & & Average tensile strength $\sigma_{1}[\mathrm{MPa}]$ & $3.09 / 3.29$ & Model Code 2010 \\
\hline & & Average residual strength $\sigma_{2}$ [MPa] & 3.44 / 3.66 & Model Code 2010 \\
\hline & & Average residual strength $\sigma_{3}$ [MPa] & $2.44 / 1.34$ & Model Code 2010 \\
\hline & & Average residual strength $\sigma_{4}[\mathrm{MPa}]$ & $2.43 / 1.61$ & Model Code 2010 \\
\hline & & Average strain $\varepsilon_{1}[\%$ o] & $0.10 / 0.11$ & Model Code 2010 \\
\hline & & Average strain $\varepsilon_{2}[\%$ ] & $0.15 / 0.15$ & Model Code 2010 \\
\hline & & Average strain $\varepsilon_{3}[\%$ ] & $0.27 / 0.39$ & Model Code 2010 \\
\hline & & Average strain $\varepsilon_{4}[\%$ ] & $20.0 / 20.0$ & Model Code 2010 \\
\hline & & Characteristic length [m] & 0.1 & Pederson (1996), Kooiman (2000) \\
\hline \multirow{12}{*}{$\begin{array}{c}\text { Model M } \\
\quad+ \\
\text { Model L }\end{array}$} & \multirow{12}{*}{$\begin{array}{c}\text { Slab } \\
\text { (SF/PF) }\end{array}$} & Average compressive strength [MPa] & $46.7 / 46.4$ & UNE 83507:2004 \\
\hline & & Average modulus of elasticity [GPa] & $29.0 / 32.0$ & UNE 83316:1996 \\
\hline & & Poisson ratio [-] & 0.2 & Model Code 2010 \\
\hline & & Average tensile strength $\sigma_{1}$ [MPa] & $3.09 / 3.07$ & Model Code 2010 \\
\hline & & Average residual strength $\sigma_{2}[\mathrm{MPa}]$ & $3.43 / 3.42$ & Model Code 2010 \\
\hline & & Average residual strength $\sigma_{3}[\mathrm{MPa}]$ & 2.44 / 1.61 & Model Code 2010 \\
\hline & & Average residual strength $\sigma_{4}[\mathrm{MPa}]$ & $2.43 / 1.83$ & Model Code 2010 \\
\hline & & Average strain $\varepsilon_{1}$ [\%o] & $0.11 / 0.10$ & Model Code 2010 \\
\hline & & Average strain $\varepsilon_{2}$ [\%o] & $0.15 / 0.15$ & Model Code 2010 \\
\hline & & Average strain $\varepsilon_{3}[\%$ ] & $0.27 / 0.38$ & Model Code 2010 \\
\hline & & Average strain $\varepsilon_{4}[\%$ ] & $20.0 / 20.0$ & Model Code 2010 \\
\hline & & Characteristic length [m] & 0.1 & Pederson (1996), Kooiman (2000) \\
\hline
\end{tabular}

\section{Numerical results}

Fig. 8 presents a comparison between the numerical and the experimental $P-\delta$ curves. The results indicate that the use of the constitutive law from the Model Code 2010 with an orientation factor $K$ equal to 1.0 leads to unsafe overestimations of the experimental results in all cases, although it is more evident for PFRC slabs. In fact, for a $10 \mathrm{~mm}$ deflection the model overestimates the load in $35.9 \%, 90.1 \%$ and $109.1 \%$ for slabs S_PF, M_PF and L_PF, respectively. For slabs S_SF, M_SF and L_SF these percentages are 42.7\%, 52.0\% and 56.8\%, respectively. The fact that the overestimation varies depending on the type of fiber is the first sign that specific design considerations are needed for PF and for SF.

These unsafe predictions may be attributed to two phenomena. First of all, assuming an isotropic fiber orientation by considering an orientation factor equal to 1.0 is not suitable for the slabs tested, despite being common practice in the design. This was already reported by Blanco et al. (2015b) and by Pujadas et al. (2014a) for the case of the RILEM (RILEM 2003) and the Spanish recommendations (CPH 2008). Moreover, the flexural response of the small beam used in the characterization test is not representative of the structural behavior of slabs. The need to consider these differences between standard tests and full-scale elements was also pointed out by Wille and Parra-Montesinos (2012) through the use of a correction factor such as the one proposed in AFGC-SETRA (2002). 

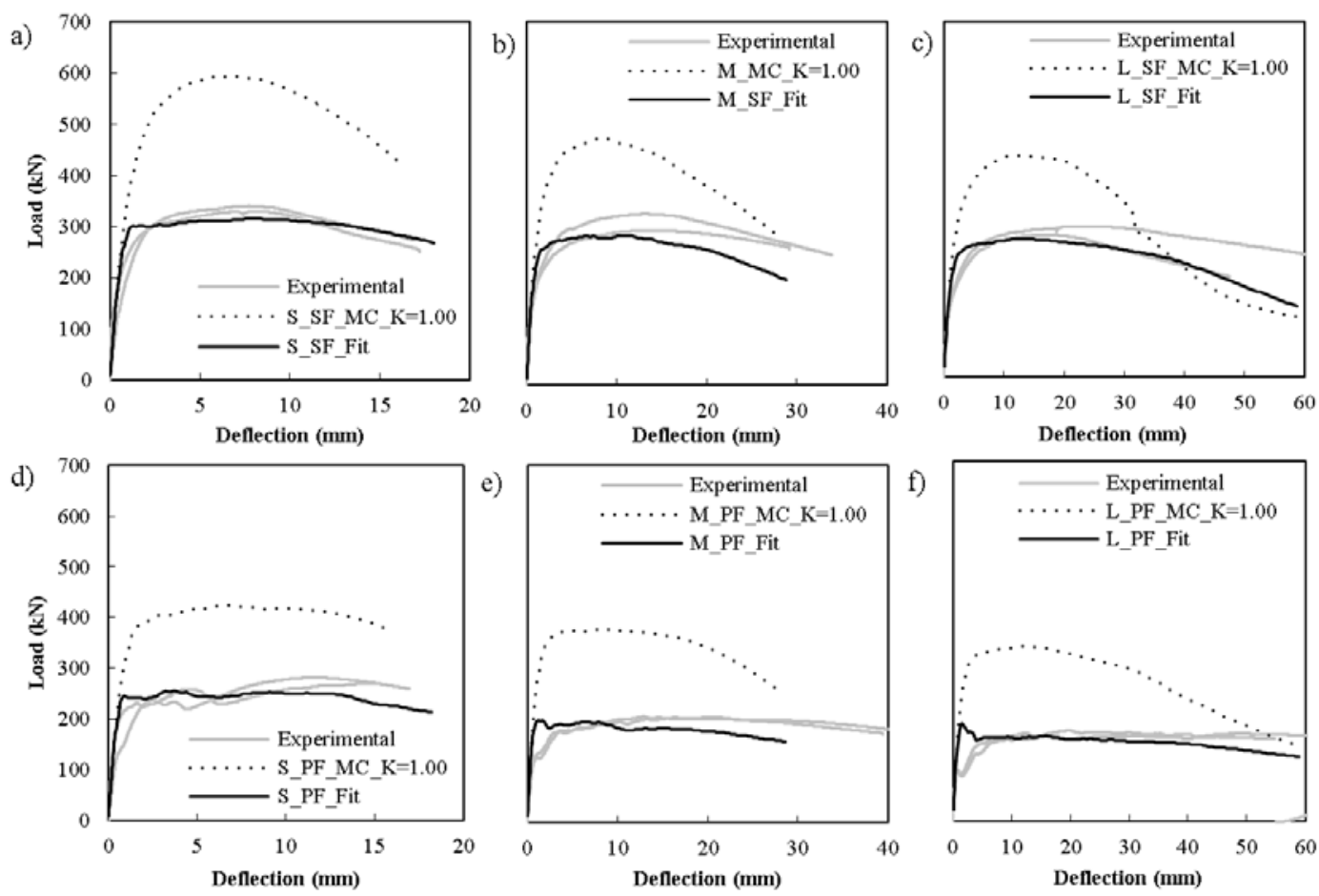

Fig. 8 Experimental P- $\delta$ curves and simulation provided by ATENA with the constitutive laws from the MC 2010 for slabs a) S_SF, b) M_SF, c) L_SF, d) S_PF, e) M_PF and f) L_PF

Considering the above, one might ask what constitutive model fits the experimental curves of the SFRC and PFRC slabs. In order to answer this question, the inverse approach was applied and a numerical fit of the experimental curves was conducted to determine the values of the parameters of the constitutive diagram that gives numerical results similar to the experimental measurements.

The numerical fit consisted of varying certain parameters of the stress-strain diagram (see Fig.6) used in the finite element models in order to find the numerical curve that approach the experimental curve. Notice that some of the parameters of the constitutive diagram do not affect the post-cracking behavior of the slabs at large deflections since they correspond to the linearelastic stage of the response, namely $\sigma_{1}, \sigma_{2}, \varepsilon_{1}$ and $\varepsilon_{2}$. For this reason, such parameters remained constant in the numerical fit and were defined according to the Model Code 2010 (see Table 4). The remaining parameters in Fig. 6 represent the contribution of the fibers to the bearing of stresses after cracking. Studies Blanco et al. (2015b) and Pujadas et al. (2014b) have shown that $\varepsilon_{3}$ and $\varepsilon_{4}$ have a small influence on the results and, therefore, were also assumed constant. In this context, the parameters selected as variables of the numerical fit were $\sigma_{3}$ and $\sigma_{4}$. This is in line with the orientation factor $(K)$ proposed in the Model Code 2010, which is applied on $\sigma_{3}$ and $\sigma_{4}$ in order to consider favorable or unfavorable fiber orientations. Several combinations of $\sigma_{3}$ and $\sigma_{4}$ were input to the finite element model until the best fit with the experimental results was found.

Fig. 8 shows the P- $\delta$ curves obtained with the finite element simulation after the numerical fit. It is clear that the new numerical curves reproduce satisfactorily the post-cracking experimental behavior of the slabs even for large displacements. This is particularly evident for PFRC slabs. 
The SFRC slabs present higher variability in the post-cracking stage and, therefore, the fit of the experimental curves is less accurate. In any case, the numerical fit remains on the safe side.

The constitutive diagram that yielded the best fit are included in Table 5 and graphically represented in Fig.9. A general overestimation of the performance of the FRC is observed in the constitutive diagrams from the Model Code 2010 assuming a $K$ of 1 . Such overestimation may be partially attributed to the fact that the constitutive diagram is based on the performance of small-scale beams, not slabs.

Table 5. Constitutive diagram obtained with the numerical fit of the experimental curves

\begin{tabular}{|c|c|c|c|c|c|c|c|c|}
\hline Slab & $\sigma_{1}[\mathrm{MPa}]$ & $\sigma_{2}[\mathrm{MPa}]$ & $\sigma_{3}$ [MPa] & $\sigma_{4}$ [MPa] & $\varepsilon_{1}[\% \circ]$ & $\varepsilon_{2}[\%]$ & $\varepsilon_{3}[\% \circ]$ & $\varepsilon_{4}[\% 0]$ \\
\hline S_SF & 3.09 & 3.44 & 1.00 & 0.50 & 0.10 & 0.15 & 0.27 & 20.0 \\
\hline M_SF & 3.09 & 3.43 & 1.10 & 1.45 & 0.11 & 0.15 & 0.27 & 20.0 \\
\hline L_SF & 3.09 & 3.43 & 1.20 & 1.50 & 0.11 & 0.15 & 0.27 & 20.0 \\
\hline S_PF & 3.29 & 3.66 & 0.30 & 1.15 & 0.11 & 0.15 & 0.39 & 20.0 \\
\hline M_PF & 3.07 & 3.42 & 0.30 & 1.25 & 0.10 & 0.15 & 0.38 & 20.0 \\
\hline L_PF & 3.07 & 3.42 & 0.30 & 1.40 & 0.10 & 0.15 & 0.38 & 20.0 \\
\hline
\end{tabular}
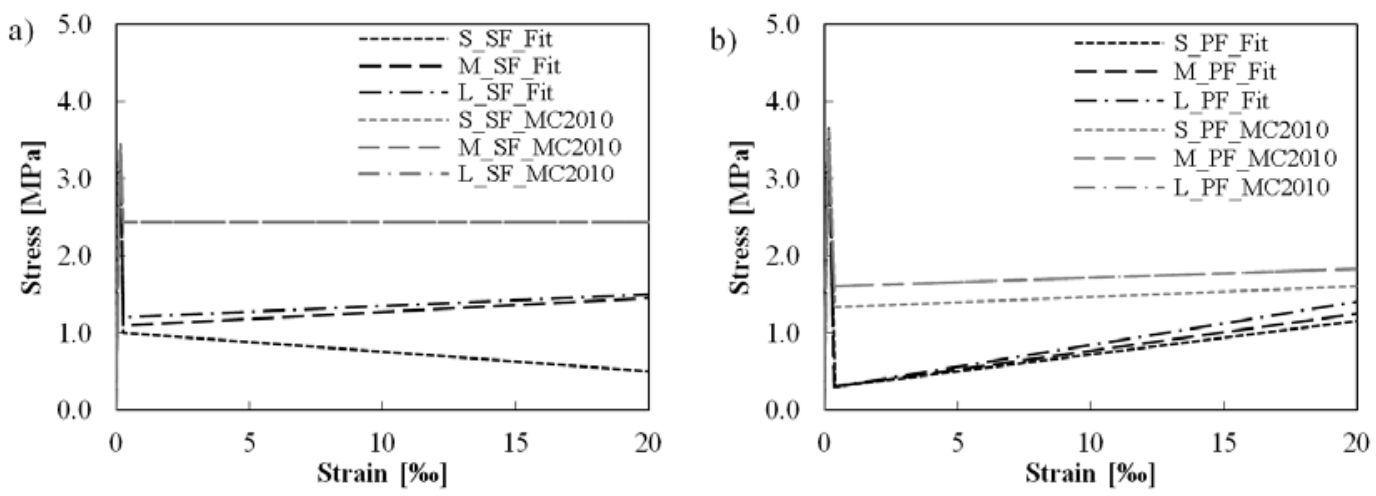

Fig. 9 Constitutive models obtained with the numerical fit for: a) SF and b) PF

The divergence between the diagram from the Model Code 2010 assuming a $K$ of 1 and the diagram from the numerical fit are particularly significant in terms of the parameter $\sigma_{3}$, which represents the contribution of the fibers just after the cracking of the matrix and the subsequent loss of stiffness. This point also coincides with the biggest differences in the pullout behavior of $\mathrm{PF}$ and SF. At this point, the overestimation in the case of PFRC is approximately 2 times bigger than that of the SFRC. These results suggest that the constitutive diagram for the design of PFRC is less representative of the real sectional response than the diagram for SFRC. Consequently, a less safe design would be obtained if the existing diagram was applied for the design of PFRC slabs, assuming the same $K$ for both materials.

\section{PROPOSAL OF CORRECTION FACTORS}

Table 6 presents the correction factors that should be applied to the original constitutive models of the Model Code 2010 to obtain each one of the curves presented in Figure 8. Michels et al. (2012), Pujadas et al. (2014a) and Blanco et al. (2015a, 2015b) have already shown that correction factors might be needed to properly reproduce the real structural response. The present study confirms these findings and suggests that different factors might be required depending on the strain level and on the fiber type. For instance, the large overestimation of the 
contribution of the fibers after the cracking leads to a correction factor $\left(\sigma_{3, M C 2010} / \sigma_{3, \text { fit }}\right)$ over 2.0 in the case of the SFRC slabs and over 4.0 in the case of the PFRC slabs. Conversely, the correction factors associated to $\sigma_{4}$ present similar values regardless of the type of fiber, with the exception of slab S_SF.

Table 6. Correction factors applied on the original constitutive diagram to obtain the fit

\begin{tabular}{ccc}
\hline Slab & $\boldsymbol{\sigma}_{3, \mathbf{M C 2 0 1 0}} / \boldsymbol{\sigma}_{\mathbf{3}, \text { fit }}[-]$ & $\boldsymbol{\sigma}_{4, \mathbf{M C} 2010} / \boldsymbol{\sigma}_{\mathbf{4}, \text { fit }}[-]$ \\
\hline S_SF & 2.44 & 4.76 \\
M_SF & 2.22 & 1.67 \\
L_SF & 2.03 & 1.61 \\
\hline S_PF & 4.46 & 1.39 \\
M_PF & 5.35 & 1.47 \\
L_PF & 5.35 & 1.30 \\
\hline
\end{tabular}

Based on the previous findings, values of correction factors for the modeling of FRC slabs are proposed for steel fibers and plastic fibers. The correction factor associated to $\sigma_{3}$ is in average around 2.2 for the SFRC slabs, whereas for the PFRC this value ranges between 4.5 and 5.5 according to the results obtained in Table 6. Conversely, the correction factor associated to $\sigma 4$ exhibits similar values for both types of fibers, with the exception of the value corresponding to S_SF. Without considering the latter, the range of values for $\sigma_{4}$ could be set between 1.3-1.7, as summarized in Table 7.

Table 7. Correction factors proposed for the design of FRC slabs

\begin{tabular}{ccc}
\hline Fiber & $\boldsymbol{K} \boldsymbol{\sigma}_{3}[-]$ & $\boldsymbol{K} \boldsymbol{\sigma}_{4}[-]$ \\
\hline SF & 2.2 & $1.3-1.7$ \\
PF & $4.5-5.5$ & \\
\hline
\end{tabular}

Although further research is required in order to accurately define the values of these factors, the present study provides an order of magnitude of how distant the predictions of the current design approaches may be from the actual behavior of full-scale concrete slabs reinforced only with structural fibers.

\section{CONCLUSIONS}

This study showed the repercussion of using steel or plastic fibers as the only reinforcement in concrete slabs from two perspectives: real structural behavior and design. The experimental studies confirm a larger redistribution capacity of stresses in SFRC slabs, also characterized by a greater number of secondary cracks. The loss of stiffness observed just after cracking in the elements with PF leads to significant crack openings and damage of the cross section before the transmission of stresses becomes effective, thus limiting the formation of secondary cracks and the redistribution capacity of the element.

The constitutive law proposed in the Model Code 2010 leads to unsafe predictions of the flexural behavior of the slabs for both types of fiber when an isotropic orientation is assumed. This confirms the need for correction factors (or orientation factors as the Model Code 2010 suggests) taking into account the differences in the orientation and structural performance of the characterization of small-scale specimens and of the full-scale slabs. The results presented here 
go a step beyond in this direction, suggesting that different correction factors are needed depending on the strain level and the type of fiber.

In fact, the overestimations of the constitutive diagram for $\sigma_{3}$ (just after cracking of the concrete matrix has occurred) is two times bigger in the case of slabs with PFRC than in slabs with SFRC. The differences in the overestimation for PFRC and for SFRC reduce as the crack width increases. The larger difference for $\sigma_{3}$ may be attributed to the loss of stiffness shown by the PF until the bridging of stresses is effectively established, i.e. for low strain levels. This does not mean that PF are not valid for structural purposes. It only indicates that the constitutive diagram developed from the experience with SFRC - a material less prone to such changes in stiffness for typical fiber contents - might require further correction or adaptation in the case of PFRC.

Based on the back analysis performed with the experimental results, correction factors were proposed for each type of fibers and strain level. The correction factors for $\sigma_{3}$ are 2.2 for SF and around 5 for PF, whereas a value of approximately 1.5 is obtained for $\sigma_{4}$ for both types of fiber. The high magnitude of the correction factors found highlight that the design of FRC elements with shapes, sizes and boundary conditions different from those of small-scale tests must be treated with care. The direct application of constitutive laws assuming isotropic conditions should be avoided since it may lead to unsafe designs. Instead, a corrected diagram should be applied, considering factors like the ones derived in the present work as a result of a larger database of real-scale experimental results with different types of fibers.

\section{ACKNOWLEDGMENTS}

The authors of this document wish to show their gratitude for the economic support received through the Research Project BIA2010-17478: Construction processes by means of fiber reinforced concretes. The authors thank the company ESCOFET S.A. for their collaboration in the development of the experimental program. The first and second authors acknowledge the grant FI provided by the Comissionat per a Universitats del DIUE de la Generalitat de Catalunya i del Fons Social Europeu and the support of the Departament d'Universitats, Recerca i Societat de la Informació de la Generalitat de Catalunya.

\section{REFERENCES}

AENOR (Asociación Española de Normalización y Certificación). (2004). “UNE 83507:2004.

Hormigones con fibras. Rotura por compresión”, Madrid. (In Spanish).

AENOR (Asociación Española de Normalización y Certificación). (1996). “UNE 83316:1996. Ensayos de hormigón. Determinación del módulo de elasticidad en compresión”, Madrid. (In Spanish).

AFGC-SETRA (Association Francaise de Genie Civil - Service d'Études Techniques des Routes et Autoroutes). (2002). "Bétons Fibrés à Ultra-Hautes Performances-Ultra High Performance Fibre-Reinforced Concretes", Recommandations Provisoires-Interim Recommendations. France.

Bazant, Z.P., Oh, B.H. (1983). "Crack band theory for fracture of concrete”. Mater. Struct., 16,155-177. 
Belletti, B., Cerioni, R., Meda, A., and Plizzari, G. (2008) "Design aspects on steel fiberreinforced concrete pavements”. J. Mater. Civ. Eng., 20(9), 599-607.

Blanco, A., Pujadas, P., de la Fuente, A., Cavalaro, S., and Aguado, A. (2015a). “Assessment of the fibre orientation factor in SFRC slabs”. Composites Part B, 68, 343-354.

Blanco, A., Cavalaro, S., de la Fuente, A., Grünewald, S., Blom, C.B.M., and Walraven, J.C. (2015b) “Application of FRC constitutive models to modelling of slabs”. Mater. Struct, 48(9), 2943-2959.

Buratti, N., Mazzotti, C., and Savoia, M. (2011) Post-cracking behaviour of steel and macrosynthetic fibre-reinforced concretes. Constr. Build. Mat., 25, 2713-2722.

CEN (European Committee for Standardization). (2005a). "EN 14651:2005 Test method for metallic fiber concrete - Measuring the flexural tensile strength (limit of proportionality (LOP), residual)”, Brussels.

CEN (European Committee for Standardization). (2005b). "EN1337-3:2005 Structural bearings-Part 3: Elastomeric bearings”, Brussels.

Cervenka, V. (2000). “Simulating a response”. Concr. Eng. Int., 4(4), 45-49.

CPH (Comisión Permanente del Hormigón). (2008). “EHE-08 Instrucción 531 del Hormigón Estructural”, Madrid.

De la Fuente, A., Pujadas, P., Blanco, A., and Aguado, A. (2012a). "Experiences in Barcelona with the use of fibres in segmental linings”. Tunn. Undergr. Sp. Tech., 27, 60-71.

De la Fuente, A., Escariz, R.C., De Figueiredo, A.D., Molins, C., and Aguado, A. (2012b) “A new design method for steel fibre reinforced concrete pipes”. Constr. Build. Mater.; 30, 547555 .

De la Fuente, A., Escariz, R.C., De Figueiredo, A.D., and Aguado, A. (2013). "Design of macro-synthetic fibre reniforced concrete”. Constr. Build. Mater., 43, 523-532.

De Montaignac, R., Massicotte, B., Charron, J.-P., and Nour, A. (2012) "Design of SFRC structural elements: flexural behavior prediction”, Mater. Struct., 45(4), 623-636.

Destrée, X., and Mandl, J. (2008). "Steel fibre only reinforced concrete in free suspended elevated slabs: Case studies, design assisted by testing route, comparison to the latest SFRC standard documents", Proc., of the fib Symposium "Tailor Made Concrete Structures", Walraven and Stoelhost Eds. Taylor \& Francis Group, Amsterdam.

Di Prisco M., Dozio D., Belletti B. (2013). “On the fracture behaviour of thin-walled SFRC roof elements”. Mater. Struct., 46(5), 803-829.

FIB (Fédération Internationale du Béton / International Federation for Structural Concrete). (2010). Fib Model Code 2010, Paris.

Iyengar SRKT, Raviraj S, Ravikumar P. (1998). “Analysis study of fictitious crack propagation in concrete beams using a bi-linear $\mathrm{r}-\mathrm{w}$ relation". Proc., 3th International conference on fracture mechanics of concrete and structure (FRAMCOS III), Japan, 315-324.

Jenq, Y.S. and Shah, S.P. (1986). "Crack propagation in fiber-reinforced concrete”. J. Struct. Eng., 112, 19-34. 
Johansen, K.W. (1962). Yield line formulae for slabs. Cement and Concrete Association, London.

Kooiman, A.G. (2000). Modelling Steel Fibre Reinforced Concrete for Structural Design. Doctoral Thesis, Delft University of Technology, Delft.

Kupfer, H., Hilsdorf, H.K., Rusch, H. (1969). "Behavior of Concrete Under Biaxial Stresses”. Journal Proceedings (ACI), 66(8), 656-666.

Laranjeira, F., Aguado, A., and Molins, C. (2010a) "Predicting the pullout response of inclined straight steel fibers”. Mater. Struct., 43(6), 875-895.

Laranjeira, F., Molins, C., Aguado, A. (2010b) "Predicting the pullout response of inclined hooked steel fibers”. Cement Concrete Res., 40, 1471-1487.

Li, V.C., Wang, Y., and Backer, S. (1990) "Effect of inclining angle, bundling and surface treatment on synthetic fibre pull-out from a cement matrix”. Composites, 21(2), 132-140.

Maturana, A., Sanchez, R., Canales, J., Orbe, A., Ansola, R., and Veguería, 557 E. (2010) "Technical economic analysis of steel fibre reinforced concrete flat slabs. A real building application”. Proc., XXXVII IAHSWorld Congress on Housing Science, Santander.

Michels, J., Waldmann, D., Maas, S., and Zürbes, A. (2012) "Steel fibers as only reinforcement for flat slab construction - Experimental investigation and design”, Constr. Build. Mater., 26,145-155.

Naaman A.E., Namur, G.G., Alwan, J.M. and Najm, H.S. (1991). "Fiber pullout and bond slip I: Analytical Study”. J. Struct. Eng., 117(9), 2769-2790.

Nobilli, A., Lanzoni, L., and Tarantino, A.M. (2013) "Experimental investigation and monitoring of a polypropylene-based fiber reinforced concrete road pavement”. Constr. Build. Mater., 47, 888-895.

Pedersen, C. (1996) New production processes, materials and calculation techniques for fibre reinforced pipes. Doctoral Thesis, Technical University of Denmark, Kongens Lyngby.

Peyvandi, A., Soroushian, P., Jahangirnejad, S. (2013) "Enhancement of the structural efficiency and performance of concrete pipes through fiber reinforcement". Constr. Build. Mater., 45, 36-44.

Pujadas, P., Blanco, A., De la Fuente, A., and Aguado, A. (2011). "Cracking behavior of FRC slabs with traditional reinforcement”. Mater. Struct., 45(5), 707-725.

Pujadas, P., Blanco, A., Cavalaro, S., and Aguado, A. (2014a) "Plastic fibres as the only reinforcement for flat suspended slabs: Experimental investigation and numerical simulation”. Constr. Build. Mater., 57, 92-104.

Pujadas, P., Blanco, A., Cavalaro, S.H.P., Aguado, A., Grünewald, S., Blom, K., and Walraven J.C. (2014b) "Plastic fibres as the only reinforcement for flat suspended slabs: Parametric study and design considerations”. Constr. Build. Mater., 70, 88-96.

RILEM TC 162-TDF. (2002) "Tests and design methods for steel fibre reinforced concrete: design of steel fibre reinforced concrete using the $\sigma-\mathrm{W}$ method: principles and applications". Mater. Struct., 35, 262-278. 
RILEM TC162-TDF. (2003) "Test and design methods for steel fibre reinforced concrete- $\sigma-$ $\varepsilon$ design method-final recommendation”. Mater. Struct., 36(8), 560-567.

Singh, S., Shukla, A., Brown, R. (2004). "Pullout behavior of polypropylene fibers from Cementitious matrix”. Cement Concrete Res., 34, 1919-1925.

Soetens, T., Van Gysel, A., Matthys, S., and Taerwe, L. (2013). “A semi-analytical model to predict the pull-out behaviour of inclined hooked-end steel fibres”. Constr. Build. Mater., 43, 253-265.

Soranakom, C., Mobasher, B., and Destrée, X. (2007). "Numerical simulation of FRC Round Panel Tests and Full-Scale Elevated Slabs”, ACI Special Publication, 31-40.

Taerwe, L., and Van Gysel, A. (1996). "Influence of Steel fibres on the design 584 stress-strain curve for high-strength concrete”. ASCE J. Eng. Mech., 122(8), 695-704.

Ultkjaer, J.P., Krenk, S., Brincker, R. (1995). “Analytical model for fictitious crack propagation in concrete beams”. ASCE J. Eng. Mech., 121(1), 7-15.

Wille, K., and Parra-Montesinos, G.J. (2012). "Effect of Beam Size, Casting Method, and Support Conditions on Flexural Behavior of Ultra-High Performance Fiber-Reinforced Concrete”. ACI Mater. J., 109(3), 379-388. 